\title{
POTENSI AIR BERSIH DI KAWASAN SEGARA ANAKAN
}

\author{
Oleh: Agus Riswandi*)
}

\begin{abstract}
Abstrak
Indonesia adalah Negara tropis yang hanya memiliki dua musim saja yaitu musim hujan dan musim kemarau dengan curah hujan yang tinggi. Kondisi seperti ini menjadikan Indonesia Negara yang melimpah cadanga airnya, tidak akan mengalami kekeringan maupun kesulitan untuk mendapatkan air bersih bagi kebutuhan hidup seharihari. Hal ini berbanding terbalik dengan kenyataan yang ada, masih ada daerah yang kekeringan dan kesulitan untuk mendapatkan air bersih bagi kebutuhan sehari-hari. Fakta ini terjadi pula di kawasan Segara Anakan, dimana Kawasan Segara Anakan memiliki badan air yang luas dan memiliki banyak fungsi antara lain sebagai tempat hijrahnya ikan-ikan di perairan selatan Jawa. Namun, penduduk yang tinggal di Kawasan ini mempunyai kesulitan untuk mendapatkan air bersih, hal ini diperparah lagi dengan tingginya tingkat sedimentasi dikawasan tersebut sehingga ekosistem Segara Anakan menjadi rusak bahkan nyaris punah. Sebagai suatu kawasan yang potensial maka perlu kiranya upaya-upaya penyelamatan yang didasarkan pada identifikasi permasalahan yang muncul di kawasan tersebut dengan tetap memperhatikan kelestarian lingkungan dan kebutuhan penduduk setempat, terutama kebutuhannya terhadap pengadaan air bersih. Upaya-upaya tersebut dapat dilakukan dengan cara low solution, medium solution, dan high solution.
\end{abstract}

Kata kunci: Potensi air bersih, kawasan Sagara Anakan.

*) Agus Riswandi, adalah mahasiswa Jurusan Pendidikan Geografi FPIPS-UPI Angkatan 2005. 


\section{Pendahuluan}

Air merupakan unsur vital dalam kehidupan manusia. Seseorang tidak dapat bertahan hidup tanpa air. Karena itu, air merupakan salah satu penopang hidup bagi manusia. Bumi ini memiliki persediaan air yang sangat banyak, namun yang dapat dimanfaatkan untuk kebutuhan hidup sehari-hari terutama untuk minum hanyalah sekitar 5\% saja untuk memenuhi kebutuhan air penduduk bumi saat ini. Indonesia termasuk dalam 10 negara dengan cadangan air terbesar yaitu $15.500 \mathrm{~m}^{3} / \mathrm{kapita} / \mathrm{tahun}$, sedangkan cadangan air dunia berada pada angka $8000 \mathrm{~m}^{3} /$ kapita/tahun. Jika mengacu pada angka diatas maka Indonesia tidak seharusnya kekurangan cadangan air. Tapi pada faktanya, terutama di pulau jawa krisis air terjadi setiap tahun. Ketersediaan air di Pulau Jawa sebesar $1.750 \mathrm{~m}^{3} / \mathrm{kapita} / \mathrm{tahun}$, di bawah standar kecukupan minimal yaitu $2.000 \mathrm{~m}^{3} / \mathrm{kapita} /$ tahun. Pada tahun 2020 jumlah ini diperkirakan akan semakin menurun hingga $1.200 \mathrm{~m}^{3} / \mathrm{kapita} /$ tahun. Pada tahun 2019 diperkirakan jumlah penduduk perkotaan mencapai 150,2 juta jiwa dengan konsumsi per kapita sebesar 125 liter, sehingga kebutuhan air akan mencapai 18,775 miliar liter/hari. Kebutuhan air untuk industri akan melonjak sebesar $700 \%$ pada 2025 . Untuk perumahan naik ratarata $65 \%$ dan untuk produksi pangan naik $100 \%$ (LIPI).

Krisis kebutuhan air inipun melanda salah satu kecamatan di Kabupaten Cilacap Jawa Tengah. Saat ini krisis air bersih yang melanda Kabupaten Cilacap Jawa Tengah semakin parah terutama di Kawasan Segara Anakan Kecamatan Kampung Laut. Warga dari empat desa di kawasan ini semakin sulit memperoleh air besih yaitu Desa Ujungalang, Ujunggagak, Karanganyar, dan Panikel dengan Total penduduk Kampung Laut tidak kurang dari 15.000 jiwa dan hanya bergantung pada satu mata air yang diambil dari Nusakambangan, padahal desa-desa ini dikelilingi perairan dan hutan mangrove yang mana hutan mangrove ini salah satu hutan terluas di dunia setelah Brazil. Sejak tahun 1980-an sedimentasi di Segara Anakan mulai terlihat jelas dan sampai saat ini sedimentasi terus berlangsung sehingga mengakibatkan bertambah luasnya daratan yang mengakibatkan terjadi pertambahan penduduk dan berpengaruh pada tingginya kebutuhan air bersih. 


\section{Standar Kebutuhan Air}

Standar kelayakan kebutuhan air bersih adalah 49,5 liter/kapita/hari. Untuk kebutuhan tubuh manusia air yang diperlukan adalah 2,5 lt perhari. Standar kebutuhan air pada manusia biasanya mengikuti rumus $30 \mathrm{cc}$ per kilo gram berat badan per hari. Artinya, jika seseorang dengan berat badan $60 \mathrm{~kg}$, maka kebutuhan air tiap harinya sebanyak $1.800 \mathrm{cc}$ atau 1,8 liter. Badan dunia UNESCO sendiri pada tahun 2002 telah menetapkan hak dasar manusia atas air yaitu sebesar 60 ltr/org/hari. Direktorat Jenderal Cipta Karya Departemen Pekerjaan Umum membagi lagi standar kebutuhan air minum tersebut berdasarkan lokasi wilayah sebagai berikut:

a. Pedesaan dengan kebutuhan 60 liter / per kapita / hari.

b. Kota Kecil dengan kebutuhan 90 liter / per kapita / hari.

c. Kota Sedang dengan kebutuhan 110 liter / per kapita / hari.

d. Kota Besar dengan kebutuhan 130 liter / per kapita / hari.

e. Kota Metropolitan dengan kebutuhan 150 liter / per kapita / hari.

Berdasarkan pada Peraturan Menteri Dalam Negeri Nomor 23 Tahun 2006 tentang Pedoman Teknis dan Tata Cara Pengaturan Tarif Air Minum pada Perusahaan Daerah Air Minum BAB I ketentuan umum Pasal 1 ayat 8 menyatakan bahwa, standar kebutuhan pokok air minum adalah kebutuhan air sebesar $10 \mathrm{~m}^{3} / \mathrm{KK} / \mathrm{bln}$ atau 60 liter/orang/hr, atau sebesar satuan volume lainnya yang ditetapkan lebih lanjut oleh Menteri yang menyelenggarakan urusan pemerintahan di bidang sumber daya air. Untuk kebutuhan air minum nasional data dari Departemen PU menunjukkan, bahwa kebutuhan air minum nasional sebanyak 272.107 liter per detik, sedangkan kapasitas air minum eksistingnya sebanyak 105.000 liter perdetik.

\section{Potensi air daerah penelitian}

Curah hujan rata-rata tertinggi di Kabupaten Cilacap terjadi pada bulan Desember $(488 \mathrm{~mm})$ dan terendah bulan Juli $(43 \mathrm{~mm})$. Rata-rata curah hujan 2940 mm/tahun dengan hari hujan terbanyak terjadi pada bulan Desember sebanyak 21 hari sedangkan hari hujan paling sedikit terjadi pada bulan Juli sebanyak 2 hari, sedangkan pada bulan Agustus tidak terjadi hujan. Suhu maksimum $32,30^{\circ} \mathrm{C}$ terjadi pada bulan Mei, suhu minimum $30,20^{\circ} \mathrm{C}$ terjadi pada bulan Agustus. 
Tabel 1: Luasan rumah penduduk di Segaraanakan

\begin{tabular}{|c|c|c|c|c|c|}
\hline Desa & $<36 \mathrm{~m}^{2}$ & $36-44 m^{2}$ & $45-53 \mathrm{~m}^{2}$ & $>54 \mathrm{~m}^{2}$ & Jumlah \\
\hline Ujunggagak & 147 & 141 & 233 & 340 & 861 \\
\hline Ujungalang & 467 & 103 & 84 & 233 & 887 \\
\hline Klaces & 101 & 30 & 38 & 73 & 242 \\
\hline Panikel & 497 & 102 & 85 & 407 & 1091 \\
\hline Jumlah & 1.210 & 376 & 440 & 1.053 & 3.081 \\
\hline
\end{tabular}

Sumber : BPS Kabupaten Cilacap

Potensi air merupakan jumlah air yang tersedia, berupa air permukaan dan air tanah yang dinyatakan dalam satuan waktu satu tahun. Data di atas dapat dihitung hubungan antara potensi dengan curah hujan dan kondisi rumah.

Tabel 2: Hubungan antara potensi, curah hujan dan kondisi rumah

\begin{tabular}{|l|l|l|l|l|}
\hline $\begin{array}{c}\text { Luas Rumah } \\
(\mathrm{m} 2)\end{array}$ & $\begin{array}{l}\text { Banyaknya } \\
\text { Rumah }\end{array}$ & $\begin{array}{c}\text { Total Luas } \\
\text { Area }(\mathrm{m} 2)\end{array}$ & $\begin{array}{l}\text { Curah Hujan } \\
(\mathrm{mm} / \mathrm{tahun})\end{array}$ & $\begin{array}{c}\text { Potensi Air } \\
\text { Tertampung } \\
\left(\mathrm{m}^{3}\right)\end{array}$ \\
\hline$<36$ & 1212 & 43632 & 2.940 & 128278 \\
\hline $36-44$ & 376 & 11040 & 2.940 & 32458 \\
\hline $45-53$ & 440 & 21560 & 2.940 & 63386 \\
\hline$>54$ & 1053 & 56862 & 2.940 & 167174 \\
\hline Jumlah & 3081 & 133094 & 2.940 & 391296 \\
\hline
\end{tabular}

Dari tabel tersebut dapat diketahui potensi daya tangkapan air maksimal dengan asumsi semua rumah memiliki alat penampang air hujan sesuai dengan luas rumah tanpa adanya penyusutan tangkapan.

i). Tipe rumah $<36 \mathrm{~m}^{2}$

Daya Tampung air $=$ luas rumah $\mathrm{x}$ curah hujan

$=36 \mathrm{~m}^{2} \times 2,94 \mathrm{~m} /$ tahun

$=105,84 \mathrm{~m}^{3} /$ tahun

ii). Tipe rumah $36-44 \mathrm{~m}^{2}$

Daya Tampung air $=$ luas rumah $\mathrm{x}$ curah hujanss

$=40 \mathrm{~m}^{2} \times 2,94 \mathrm{~m} /$ tahun

$=117,6 \mathrm{~m}^{3} /$ tahun

iii). Tipe rumah $45-53 \mathrm{~m}^{2}$

Daya Tampung air $=$ luas rumah $\mathrm{x}$ curah hujan 
$=49 \mathrm{~m}^{2} \times 2,94 \mathrm{~m} /$ tahun

$=144,06 \mathrm{~m}^{3} /$ tahun

iv). Tipe rumah $>54 \mathrm{~m}^{2}$

Daya Tampung air = luas rumah $\mathrm{x}$ curah hujan

$=54 \mathrm{~m}^{2} \times 2,94 \mathrm{~m} / \mathrm{tahun}$

$=158,76 \mathrm{~m}^{3} /$ tahun

\section{Kebutuhan Air Cilacap}

Berdasarkan standar kebutuhan air tersebut, Kecamatan Kampung Laut dengan jumlah penduduk 14.907 jiwa dapat dihitung kebutuhan airnya dengan mengacu pada standar kebutuhan air, yaitu :

Kebutuhan air $=42$ liter $\times 14.907$ orang

$$
\begin{aligned}
& =626.094 \text { liter/hari }=125 \text { tangki } 5000 \mathrm{~L} / \text { hari } \\
& =228.524 .310 \mathrm{~L} / \text { tahun } \\
& =45.705 \text { tangki } 5000 \mathrm{~L} / \text { tahun untuk tahun } 2007
\end{aligned}
$$

\section{Proyeksi 10 tahun yang akan datang}

Kebutuhan air bersih penduduk di Kawasan Segara Anakan pada 10 tahun yang akan datang atau pada tahun 2018 sangat bergantung pada dua faktor utama, yaitu sedimentasi sebesar 64,73 ha/tahun (PPGL) dan juga peningkatan jumlah penduduk.

Tabel 3:Laju Sedimentasi Segara Anakan

\begin{tabular}{|l|c|c|}
\hline No. & Tahun & Luas Permukan (ha) \\
\hline 1. & 1944 & 5.350 \\
\hline 2. & 1963 & $5.632,15$ \\
\hline 3. & 1989 & 2.957 \\
\hline 4. & 1992 & 1.973 \\
\hline 5. & 1994 & $1.925,60$ \\
\hline 6. & 1999 & $1.595,10$ \\
\hline 7. & 2002 & $1.596,11$ \\
\hline 8. & 2010 & 0 (tidak ada laguna) \\
\hline
\end{tabular}

Sumber : PPPGL

Tabel menunjukkan bahwa pada tahun 2010 Laguna Segara Anakan telah menjadi daratan total tanpa ada lagi badan air, sehingga penduduk akan bertambah banyak baik itu penduduk asli maupun 
ditambah dengan penduduk pendatang. Jika mengacu pada laju pertumbuhan penduduk tahun 2007 yaitu sebesar 2,7\% dan angka laju pertumbuhan tersebut dianggap tetap hingga tahun 2017, maka jumlah penduduk akan berjumlah 19.458 jiwa. Sehingga proyeksi kebutuhan air bersih di kawasan segara anakan pada tahun 2017 yaitu sebesar 298.288. $\mathrm{m}^{3}$ dengan perhitungan.

Kebutuhan air $=42$ liter $\mathrm{x} 19.458$ orang

$$
\begin{aligned}
& =817.229 \mathrm{~L} / \text { hari }=163 \text { tangki } 5000 \mathrm{~L} / \text { hari } \\
& =298.288 .728 \mathrm{~L} / \text { tahun } \\
& =59.658 \text { tangki } 5000 \mathrm{~L} / \text { thn }(2017)
\end{aligned}
$$

\section{Upaya Pemecahan Masalah \\ a. Low Solution}

1) Pengambilan air secara langsung

Cara ini dianggap paling efektif dilakukan pada waktu sekarang ini, yaitu dengan mengambil air ke sumber air yaitu di pulau Nusakambangan dengan menggunakan alat angkut berupa perahu kecil (compreng). Teknik ini memiliki banyak kekurangan jika dilakukan untuk jangka 10 tahun ke depan, diantaranya adalah biaya sewa perahu yang sangat mahal antara Rp 20.000 - Rp 50.000 per perahu setiap kali angkut air sebesar 500 liter, hal ini dikarenakan tingginya beban BBM. Teknik seperti ini pun akan hilang dan berhenti dengan sendirinya, seiring dengan tingginya tingkat sedimentasi. Jika prediksi pada tahun 2010 segara anakan akan menjadi daratan, maka pada tahun yang sama teknik ini sudah tidak dapat lagi digunakan, dan jika masih belum ditemukan solusi penggantinya, maka pada tahun yang sama penduduk akan mengalami kekurangan air yang sangat besar.

2) Sumur

Pembuatan sumur yang dilakukan warga mengalami kendala sangat besar, yaitu sumur yang telah digali hingga 11 meter tapi masih belum di dapatkan air, dan kalaupun air didapatkan, air tersebbut sudah terakontaminasi oleh air laut sehingga berasa payau bahkan ada yang berasa asin.

3) Menampung air Hujan

Teknik ini merupakan teknik sederhana dan sangat ramah lingkungan, dan dapat berlangsung lama tanpa terpengaruh 
perubahan Segara Anakan yang diprediksi akan menjadi daratan pada tahun 2010. Tapi, teknik ini sangat bergantung pada alam, karena hanya dapat berfungsi pada musim hujan saja. Teknik ini dilakukan dengan cara membuat penampungan air hujan berupa bak penampungan maupun talang penangkapan air, kemudian air tersebut di alirkan ke tempat penampungan air. Teknik ini saudah dilakukan oleh sebagian kecil penduduk.

\section{b. Medium Solution}

Medium solution merupakan alternatif pemecahan masalah menengah dalam pemenuhan kebutuhan air di Segara Anakan, diantaranya:

1) Tangki terapung

Pengadaan tangki air bersih terapung dari PDAM. Penduduk Kampung laut biasa mendapatkan air dengan biaya $\mathrm{Rp}$ $30.000,-/ 500$ liter air atau penduduk sekitar biasanya menyebut satu fiber, yang digunakan oleh 4 orang dan dapat mencukupi hingga 3 hari. Hal ini sama dengan setiap jiwa menggunakan air sebanyak $42 \mathrm{~L} /$ hari atau seharga $\mathrm{Rp} 2520$,-/hari/ jiwa. Jika menggunakan tangki terapung yang berkapasitas 5000 liter maka untuk memenuhi kebutuhan air warga yang berjumlah lebih kurang 14.907 jiwa dibutuhkan air bersih sebanyak 630.000 liter/per hari atau setara dengan 126 tangki air. 1 tangki air biasanya di jual dengan harga Rp 85.000,- di daerah Jawa Barat, Jika 1 tangki air di Cilacap diasumsikan dua kali lipat harga di Jawa Barat sekitar Rp 170.000,- per 5000 liter, maka setiap 1 liter setara dengan $\mathrm{Rp} 34,-$. Jika setiap jiwa di asumsikan sama yaitu mengkonsumsi air sebanyak 42 liter per hari, maka setiap jiwa hanya mengeluarkan biaya sebesar $\mathrm{Rp}$ 1428,-/hari dengan menggunakan tangki terapung atau lebih irit Rp 1092,-/hari dari pada mengambil sendiri ke Nusakambangan atau lebih hemat sekitar $44 \%$ dari biaya dengan mengambil sendiri ke Nusakambangan.

\section{2) Sumur Bor}

Percobaan pembuatan sumur bor pernah dilakukan oleh warga yang didukung oleh pemerintah setempat, tapi hasilnya nihil, pemboran yang sudah dilakukan lebih dari 20 meter belum 
menghasilkan air dan kalaupun ada air tapi berasa payau bahkan asin. Pemboran dilakukan di Dusun Mekarsari Desa Panikel yang merupakan wilayah tanah timbul, sehingga jika di buat sumur bor di lokasi tersebut jelas akan terkontaminasi oleh air laut.

\section{c. High Solution}

High solution merupakan solusi yang memiliki hubungan dan campur tangan pemerintah secara penuh dalam upaya pemenuhan kebutuhan air lokal setempat. High solution yang sedang direncanakan adalah pembuatan pipa PDAM bawah laut, yang berasal baik dari Cilacap maupun dari Nusakambangan ataupun dari daerah Kawunganten. Pipa tersebut dibuat dan ditanam di bawah laut yang bersumber dari reservoir PDAM, yang disalurkan ke semua daerah tujuan baik secara langsung ke masing-masing rumah warga maupun disalurkan ke bak penampungan air yang berada di pusat dusun sehingga semua warga bisa mengambil. Tapi solusi ini memiliki beberapa hambatan diantaranya, debit air yang dapt disalurkan PDAM ketika musim kemarau sangat terbatas, dikarenakan kondisi sungai serayu yang menjadi sumber air PDAM sudah mulai berkurang debitnya, selain itu biaya instalasi pipa PDAM yang memakan biaya yang tidak sedikit.

\section{Penutup}

Sebagai suatu kawasan unik bukan hanya di Indonesia melainkan di dunia, layaknya Segara Anakan harus diperlakukan secara khusus, baik oleh pemerintah maupun penduduk yang tinggal di kawasan tersebut. Sedimentasi yang tinggi mengakibatkan multiproblem yang pemecahannya tidak mudah untuk dilakukan. Masalah yang paling sulit adalah pemenuhan kebutuhan air bersih. Sebagai upaya untuk menutupi kekurangan air bersih bagi penduduk di Kawasan Segara Anakan, dapat dilakukan sebagai program jangka pendek diantaranya adalah memaksimalkan potensi air hujan. Dengan curah hujan rata-rata pertahun sebesar $2940 \mathrm{~mm}$, maka setiap $\mathrm{m}^{2}$ lahan dapat menampung air hujan kurang lebih $3 \mathrm{~m}^{3}$, cara ini selain mudah dilakukan juga biaya yang dikeluarkan juga minimal.

Dengan jumlah penduduk yang terus bertambah, maka kebutuhan air bersih pun akan terus meningkat, sebenarnya potensi air bersih diKawasan Segara Anakan masih cukup besar, baik yang 
berasal dari potensi air hujan maupun potensi air yang berada di guagua dan sungai bawah tanah di pulau Nusakambangan. Akan tetapi dalam pemanfaatannya masih kurang optimal sehingga kekurangan air bersih akan terus terjadi.

\section{DAFTAR PUSTAKA}

Arikunto. S. 1997. Prosedur Penelitian suatu Pendekatan Praktek. Jakarta: Rieneka Cipta.

Arsyad, S. 1989. Konservasi Tanah dan Air. Bogor: IPB Press.

Diktat Geomorfologi. Klasifikasi Satuan dan Detil Geomorfologi.

Hasan, Iqbal. 2004. Analisis Penelitian Dengan Statistik. Jakarta: Bumi Aksara.

Kodoatie, R. J. dan Sjarief, R. 2005. Pengelolaan Sumberdaya Air Terpadu. Yogyakarta: Andi.

Peraturan Pemerintah Nomor 82 tahun 2001, tentang Pengelolaan Kualitas Air dan Pengendalian Pencemaran.

Peraturan Menteri Dalam Negeri Nomor 23 Tahun 2006, tentang Pedoman Teknis dan Tata Cara Pengaturan Tarif Air Minum pada Perusahaan Daerah Air Minum BAB I ketentuan umum Pasal 1 ayat 8.

Seyhan Ersin, 1990. Dasar-dasar Hidrologi. Yogyakarta: Gajah Mada University Press.

Soekardi, R., Nota Singkat Tentang Penyediaan Air Di Daerah Cilacap Dan Gombong. Pusat Djawatan Geologi Bagian Geo Hidrologi.

Sosrodarsono Suryono, 1987. "Hidrologi Untuk Pengairan" Jakarta: PT Pradnya Paramita.

Badan Pengelolaan Kawasan Segara Anakan dan BPS Kabupaten Cilacap. 2007. Survey Sosial Ekonomi Rumah Tangga Daerah (SUSEDA) Di Kawasan Segara Anakan.

http://ciptakarya.pu.go.id/ pam/MDG/About\%20MDG.htm http://www.pontianakpost.com/berita/index.asp?Berita $=O p i n i \& i$ $d=16610$. 